\title{
Imaging the neurochemical brain in health and disease
}

\author{
PM Grasby
}

\begin{abstract}
Neurochemical transmission is a fundamental element of brain organisation that has been relatively unexplored in the living human brain. Continuing advances in radionuclide imaging, particularly positron emission tomography (PET) and single photon emission tomography (SPET), mean that elements of neurochemical transmission can now be directly measured in vivo. With these techniques convincing abnormalities of monoaminergic neurotransmitter systems have been revealed in illnesses such as Parkinson's disease and schizophrenia. Furthermore, mechanisms of drug action and treatment responses can be monitored in vivo. This brief review describes some of our recent attempts to image the neurochemical brain in health and disease at the MRC Cyclotron Unit, Hammersmith Hospital, London.
\end{abstract}

KEY WORDS: neurochemistry, brain imaging, PET, depression, schizophrenia, Parkinson's disease, dopamine, serotonin

\section{The importance of brain chemistry}

From many perspectives, the neurochemical brain is an important contemporary research theme in biology and medicine. For example, from the perspective of molecular biology, about $50 \%$ of human genes code for products expressed in the brain ${ }^{1}$. These genes influence diverse and subtle processes from brain development to language function and aspects of personality ${ }^{2-4}$. Furthermore, neurochemistry is putatively altered or is the target of treatment in many neuropsychiatric disorders which present a significant health burden worldwide. It is estimated that about $15 \%$ of the world health burden, assessed through disability-adjusted life years, is the result of neuropsychiatric disorders ${ }^{5}$, a figure that is comparable to the burden induced by cardiovascular disease. Finally, it is a common but contentious perception that much of human behaviour can be reduced to the activities of neurochemicals in the brain.

We know, at present, of approximately 100 neurotransmitters in the human brain. They interact with at least 300 neuroreceptor subtypes ${ }^{6}$. Although we take this plethora of brain neurotransmitters for granted, it was only in the 1940s that the first neurotransmitter, acetylcholine, was identified. Subse- quently, in the 1950s, the monoamines, dopamine and serotonin were implicated as neurotransmitters. However, not until the 1970s was it fully appreciated that diverse chemicals, particularly the neuropeptides, could act as neurotransmitters. Since then, glutamate and $\gamma$-amino-butyric acid have been added to the list. Most recently, nitric oxide, a gas, has been shown to be a neurotransmitter. Such a large number of neurochemicals presents a formidable problem when trying to understand the specific role each neurotransmitter system might play in brain function.

\section{The technology of PET}

Perhaps the most powerful tool for investigating neurotransmitter function in man is $\mathrm{PET}^{7}$. It is a technologically demanding tool, which requires:

- a medical cyclotron (particle accelerator) to produce short-lived positron-emitting radionuclides such as ${ }^{11} \mathrm{C},{ }^{15} \mathrm{O}$ or ${ }^{18} \mathrm{~F}$

- automated radiochemistry to incorporate these radionuclides into molecules of biological interest, eg glucose or a drug that binds to specific receptor populations

- a PET camera to detect the decaying positrons (via gamma ray emission) and mathematical modelling to use the kinetic information about the radiotracer's fate in the brain to quantify a biological aspect of the tracer's behaviour.

Although the spatial resolution of modern PET cameras is only millimetres and the temporal resolution is seconds to minutes, the technique does offer exquisite neurochemical sensitivity and specificity, being able to measure concentrations of select neurochemicals in the sub-nanomolar range in living brain tissue. A typical PET image is illustrated in Fig 1,

\section{Key Points}

Elements of neurotransmission can be directly measured in vivo with PET and SPET

Monoaminergic receptor systems are a focus for PET and SPET studies of neuropsychiatric illness

Pathophysiology, drug action and treatment responses are amenable to study with modern neurochemical in vivo imaging techniques 
superimposed on the subject's magnetic-resonance structural image to reveal the distribution of the radiotracer ${ }^{11} \mathrm{C}$ diprenorphine, which binds to mu, delta and kappa opioid receptors in the brain. Although such images are often used in publications, it is the quantification of the kinetic information contained in the images that is the ultimate goal of PET. Quantification uses the kinetic behaviour of the radiotracer in the brain to measure a variable of biological interest. One measure frequently used to index receptors is the binding potential (BP), which is proportional to the Bmax (total number of receptors) over $\mathrm{Kd}$ (1/affinity) of the radiotracer for the specific receptor population to which it binds ${ }^{8}$. Quantification requires the development of plausible biological and mathematical models of how the radiotracer behaves in the brain. As such, models often have a trade-off between the precision of the biological parameter measured and the reproducibility of those measurements.

PET is a versatile technique, with applications chiefly limited by the availability of radiotracers for the particular neurochemical systems being investigated. This versatility is illustrated by the examples below.

\section{Receptor occupancy - testing drug action in vivo}

The goal of receptor-occupancy studies is to measure the extent to which a drug binds to specific receptor sites in the human brain in vivo. Such studies now play a major role in centralnervous-system drug development and in evaluating the mechanisms of action of psychotropic drugs. In some cases, understanding the mechanisms of drug action can give insights into the pathophysiology of the disease being treated.

Our recent occupancy studies have investigated whether the beta blocker pindolol occupies 5-hydroxytryptamine 1A $\left(5-\mathrm{HT}_{1 \mathrm{~A}}\right)$ receptors in the human midbrain raphe 5-HT system. Interest in this possible site of drug action comes from clinical trials using pindolol as a novel antidepressant augmentation strategy in combination with selective serotonin reuptake inhibitors (SSRIs) ${ }^{9}$. Chronic SSRI antidepressant treatment is thought to work by increasing 5-HT levels in the terminal areas of ascending 5-HT neurons via blockade of the terminal 5-HT reuptake site. However, 5-HT release is also under the control of $5-\mathrm{HT}_{1 \mathrm{~A}}$ autoreceptors on 5-HT neurons in the raphe nucleus which, in the presence of 5-HT, have a tonic inhibitory effect on 5-HT release. Thus, when given acutely, SSRIs stimulate the inhibitory $5-\mathrm{HT}_{1 \mathrm{~A}}$ autoreceptors via the increased $5-\mathrm{HT}$ in the vicinity of the raphe, which 'dampens or brakes' further 5-HT release from terminal areas (Fig 2a). With chronic SSRI treatment, however, there is preclinical evidence that the $5-\mathrm{HT}_{1 \mathrm{~A}}$ autoreceptors are desensitised and, hence, the brake on further 5-HT release is removed, allowing sustained elevation of 5-HT in terminal regions $\mathrm{s}^{10,11}$.

Pindolol is well known as a beta blocker for treating hypertension but, like some other beta blockers, it also has nanomolar affinity for the $5-\mathrm{HT}_{1 \mathrm{~A}}$ receptor, where it may act as an antagonist. Pindolol's affinity for the 5- $\mathrm{HT}_{1 \mathrm{~A}}$ receptor led pharmacologists and psychiatrists to propose that it might be a useful novel antidepressant when combined with an SSRI (Fig 2a) ${ }^{12,13}$. Pindolol, by blocking the $5-\mathrm{HT}_{1 \mathrm{~A}}$ autoreceptor, might antagonise the SSRI-induced acute stimulatory effects of raised 5-HT on the inhibitory autoreceptor, and thus remove any brake on further 5-HT release. This might speed up or enhance any SSRI antidepressant effect.

This working hypothesis of pindolol's action critically depends on the in vivo demonstration that pindolol will bind to the $5-\mathrm{HT}_{1 \mathrm{~A}}$ autoreceptor in the human brain at the doses used in the clinical trials of augmentation of SSRI action. It has been possible to test this hypothesis using the selective radiotracer ${ }^{11} \mathrm{C}$-WAY 100635 , which images $5-\mathrm{HT}_{1 \mathrm{~A}}$ receptors in the human brain, including those in the raphe nuclei (Fig $2 \mathrm{~b})^{14}$. We tested a
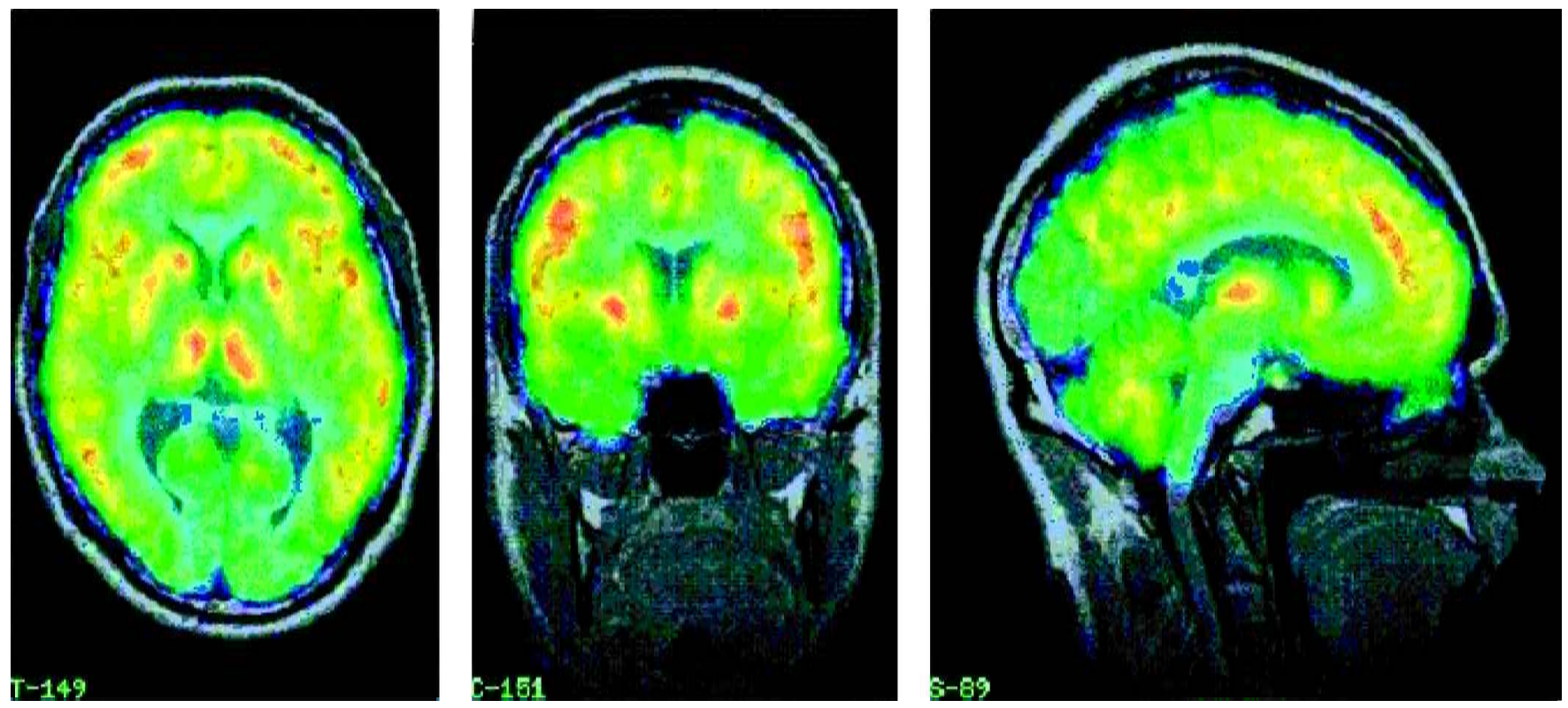

Fig 1. Positron emission tomography (PET). ${ }^{11} \mathrm{C}$-diprenorphine binding to opioid receptors in the human brain. Colour reflects density of binding. The grey image is an MRI structural image of the subject's brain coregistered with the ${ }^{11} \mathrm{C}$-diprenorphine PET image. 
range of doses of pindolol, including those used to augment SSRI action in clinical trials, for occupancy at the $5-\mathrm{HT}_{1 \mathrm{~A}}$ autoreceptor site. At the highest dose, $20 \mathrm{mg}$, pindolol achieved significant occupancy $(40 \%)$ at the autoreceptor $5-\mathrm{HT}_{1 \mathrm{~A}}$ site; however, at the lower doses used in clinical trials the occupancy achieved was very low and highly variable from subject to subject (Fig 2c) ${ }^{15}$. We concluded that a much higher pindolol dose would be required for a consistent and robust effect at the $5-\mathrm{HT}_{1 \mathrm{~A}}$ autoreceptor site. However, a drawback of giving higher doses would be that beta-blocking side effects would be more likely. This occupancy result may explain the somewhat variable outcomes of clinical trials or, alternatively, suggests that the present mechanistic explanation for pindolol's antidepressant action is incorrect.

\section{Neurotransmitter synthesis}

One of the most technologically demanding PET methods is that of measuring rates of neurotransmitter synthesis. Unfortunately, this cannot be fully achieved yet with any neurotransmitter: the closest example is the use of ${ }^{18} \mathrm{~F}$-dihydroxyphenylalanine $\left({ }^{18} \mathrm{~F}\right.$-DOPA) to index dopamine synthesis ${ }^{16}$. ${ }^{18} \mathrm{~F}$-DOPA is a radiolabelled analogue of the dopamine precursor DOPA. Unlike dopamine, DOPA crosses the blood-brain barrier and accumulates in monominergic axon terminals, where it is decarboxylated by aromatic amino-acid decarboxylase (AADC) to form dopamine and its metabolites. An intravenous injection of ${ }^{18} \mathrm{~F}-\mathrm{DOPA}$ also crosses the blood-brain barrier and accumulates in dopamine axon terminals, where it is

(a)

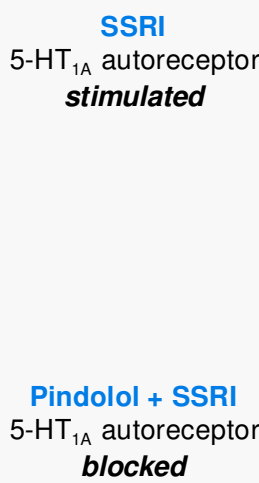

(b)

PLAC

(c)

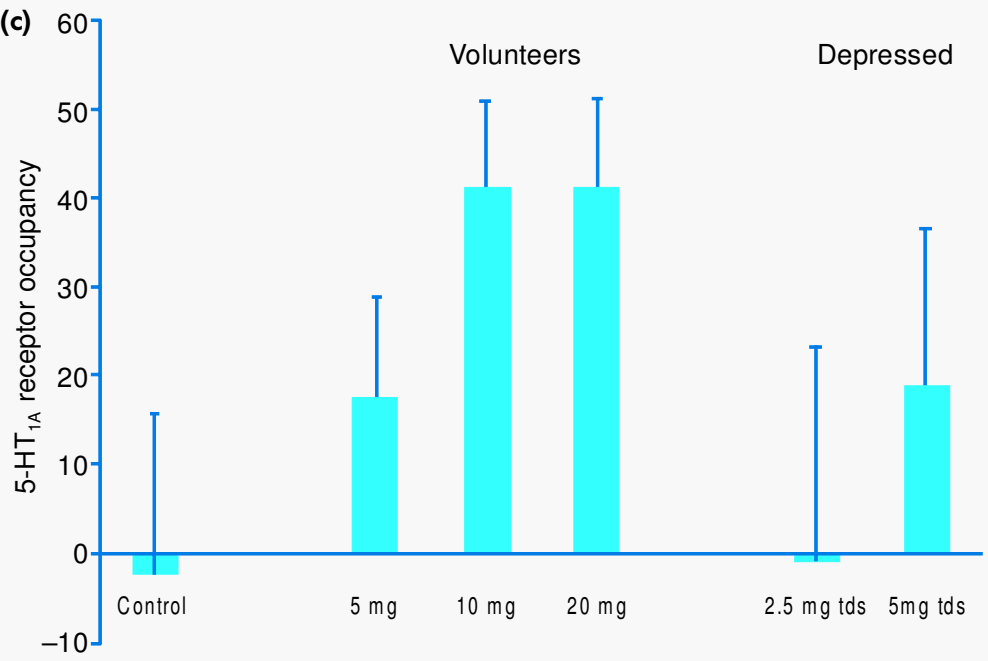

Fig 2. Testing the mechanism of action of pindolol with positron emission tomography. (a) Proposed mechanism of the antidepressant effect of the beta blocker pindolol, via 5- $\mathrm{HT}_{1 \mathrm{~A}}$ autoreceptor blockade, in the presence of a selective serotonin reuptake inhibitor. (b) ${ }^{11} \mathrm{C}-W A Y 100635$ binding to $5-\mathrm{HT}_{1 \mathrm{~A}}$ receptors, showing pindolol (PIND) and placebo (PLAC) occupancy at 5-HT ${ }_{1 \mathrm{~A}}$ receptors. (c) Dose-occupancy relationship in normal volunteers and depressed patients. The doses of pindolol used in clinical trials (2.5 mg three times daily (tds)) have minimal occupancy effects. 
decarboxylated to ${ }^{18} \mathrm{~F}$-dopamine. The uptake of ${ }^{18} \mathrm{~F}$-DOPA in the first $90 \mathrm{~min}$ after intravenous injection predominantly reflects AADC activity. The quantification that can be achieved using ${ }^{18} \mathrm{~F}$-DOPA is the measurement of an influx constant, $K_{\mathrm{i}}$. However, this radiotracer cannot be used to measure dopamine synthesis directly for two reasons: first, plasma DOPA is not the main precursor pool for dopamine synthesis (the pool is brain DOPA, which cannot yet be measured in vivo); and second, the rate-limiting enzyme for dopamine synthesis is tyrosine hydroxylase (which hydroxylates tyrosine to DOPA) not AADC. Despite such limitations, ${ }^{18} \mathrm{~F}$-DOPA can effectively index the integrity of dopamine-terminal-rich areas such as the basal ganglia, where the caudate and putamen are easily differentiated on ${ }^{18}$ F-DOPA scans (Fig 3a).

${ }^{18}$ F-DOPA was first used successfully in 1984 to image the neurochemical correlates of the 'shaking palsy', described by James Parkinson over 160 years earlier. In Parkinson's disease, there is a preferential loss of dopamine terminals in the putamen compared with the caudate in the early stages of the illness (Fig 3a). ${ }^{18} \mathrm{~F}$-DOPA is of clinical use in diagnosing Parkinson's disease, monitoring disease progression and assessing novel treatments such as neuroprotective agents and tissue grafts ${ }^{16}$. For example, my colleagues in the Cyclotron Unit, Professor Brooks and Dr Piccini, have used ${ }^{18}$ F-DOPA to assess graft survival (Fig 3a) in a patient with a long-standing history of hemi-Parkinsonism who underwent PET scanning 10 years after the grafting of fetal mesencephalic tissue into the right putamen. In this patient, ${ }^{18} \mathrm{~F}$-DOPA uptake was reduced in all basal ganglia regions apart from the vicinity of the graft, where a nearnormal uptake of ${ }^{18} \mathrm{~F}$-DOPA occurred. This patient responded well to the graft, and was able to discontinue treatment for 9 years following grafting.

Scanning using ${ }^{18} \mathrm{~F}$-DOPA has also been used in patients with schizophrenia to test a 40 -year-old hypothesis that the illness is associated with enhanced presynaptic dopaminergic activity. This hypothesis was difficult to test directly prior to the development
${ }^{18} \mathrm{~F}-\mathrm{DOPA}$ in Parkinson's disease

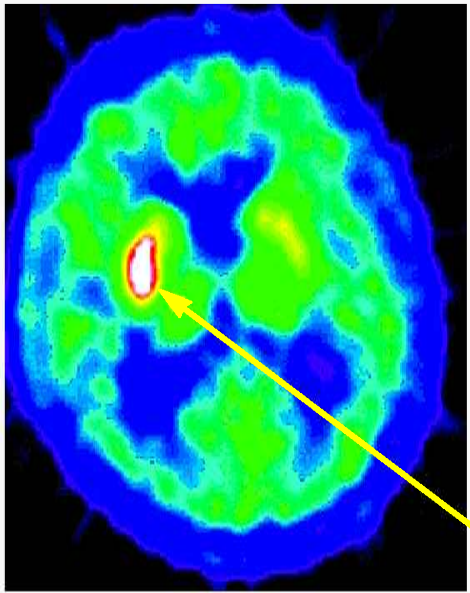

${ }^{18} \mathrm{~F}-\mathrm{DOPA}$

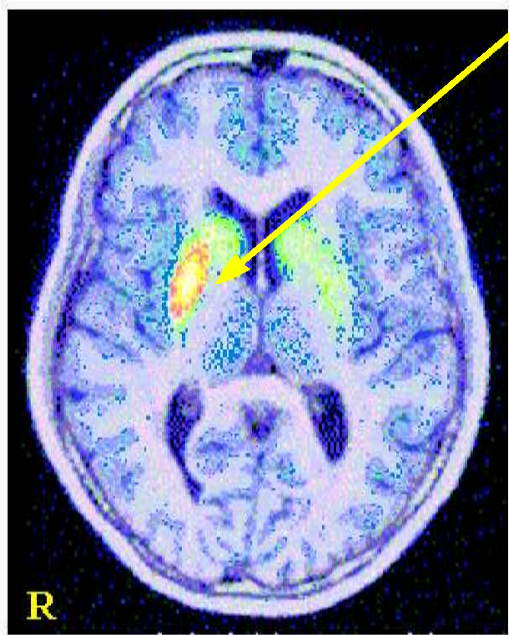

MRI

Graft
${ }^{18} \mathrm{~F}$-DOPA in schizophrenia

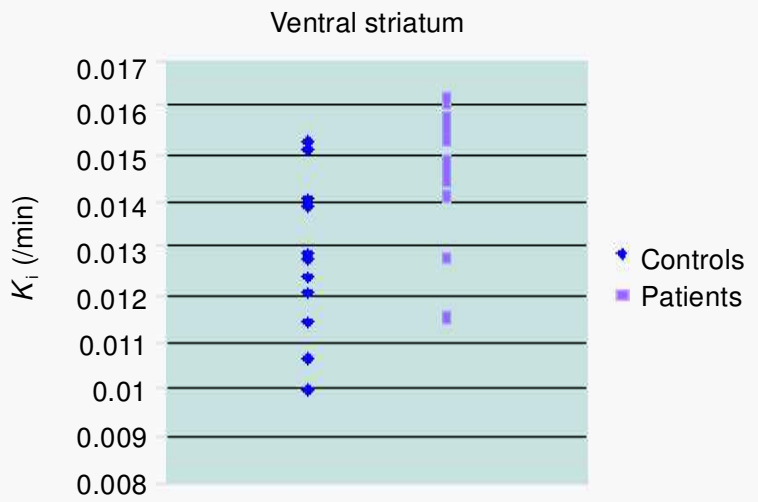

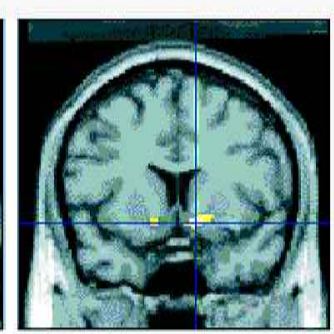
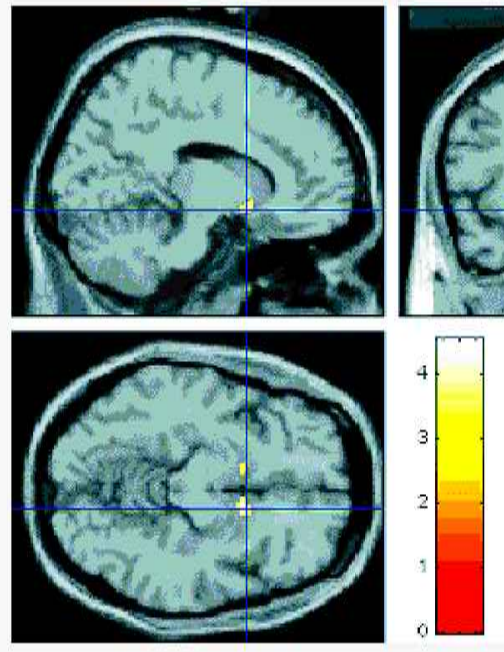

(b)

Fig. 3. ${ }^{18} \mathrm{~F}-\mathrm{DOPA}$ positron emission tomography scanning of Parkinson's disease and schizophrenia. (a) A patient with Parkinson's disease shows reduced uptake of ${ }^{18} \mathrm{~F}$-DOPA in the basal ganglia, apart from the region around a mesencephalic graft, where an enhanced ${ }^{18} \mathrm{~F}$-DOPA uptake is seen. (b) Statistical parametric map showing increased ${ }^{18} \mathrm{~F}$-DOPA uptake $\left(K_{i}\right)$ in the ventral striatum of patients with schizophrenia; the results are coregistered to a template structural MRI image. 
of radiotracers that target dopamine neurotransmission, such as ${ }^{18} \mathrm{~F}$-DOPA and other novel PET methods to be discussed later. Results from our ${ }^{18} \mathrm{~F}-\mathrm{DOPA}$ study, recently completed in 20 patients with schizophrenia, show an enhanced uptake of ${ }^{18} \mathrm{~F}$-DOPA in the ventral striatum (Fig 3b), which provides further direct support for the dopamine over-activity hypothesis and is in agreement with other studies of ${ }^{18} \mathrm{~F}$-DOPA in schizophrenia ${ }^{17}$.

\section{PET measurement of neurotransmitter release}

The above ${ }^{18} \mathrm{~F}$-DOPA examples, illustrating the survival of a tissue graft in Parkinson's disease and increased AADC activity in schizophrenia, do not, of course, directly sample synaptic dopamine release, a direct manifestation of the functional consequences of altered dopamine neurotransmission. One of the most exciting developments in PET research in recent years has been the ability to index synaptic dopamine release in the living brain. This effect can be seen with relatively few radiotracers, one of which is ${ }^{11} \mathrm{C}$-raclopride, a dopamine $\mathrm{D}_{2}$ antagonist, the binding of which is sensitive to endogenous levels of dopamine ${ }^{18,19}$. Theoretically, under conditions of enhanced synaptic-dopamine release (eg following an amphetamine challenge) the increased occupancy of dopamine $D_{2}$ receptors by dopamine will result in fewer receptors being available to bind to ${ }^{11} \mathrm{C}$-raclopride and, hence, the binding of this radiotracer should decrease. Indeed, it has proved possible to observe this effect in the human brain (Fig 4a), which naturally led us to question whether dopamine release could be detected under not only pharmacological but also behavioural challenges.

Primate work, particularly electrophysiological recordings from awake behaving monkeys, has identified behavioural conditions that provoke increased dopamine activity ${ }^{20,21}$. These include reward, learning and novelty. We encapsulated these psychological components in a financially rewarded 'video game' task as the behavioural manipulation in a PET experiment using ${ }^{11} \mathrm{C}$-raclopride. We discovered that binding of ${ }^{11} \mathrm{C}$-raclopride was reduced in the presence of the video game, compared with a baseline condition without reward, learning and novelty (Fig 4c). Furthermore, the reduction in binding of ${ }^{11} \mathrm{C}$-raclopride correlated with the subjects' performance in the game: those subjects who performed well showed a greater change in binding ${ }^{22}$. This result, thus, defines some of the conditions under which dopamine will be released in the human brain. Such radiotracer 'displacement' techniques have a ready application in studying disease processes, some recent examples being the assessment of graft function in Parkinson's disease and of dopamine release in schizophrenia.
${ }^{11} \mathrm{C}$-raclopride binding in normal volunteer
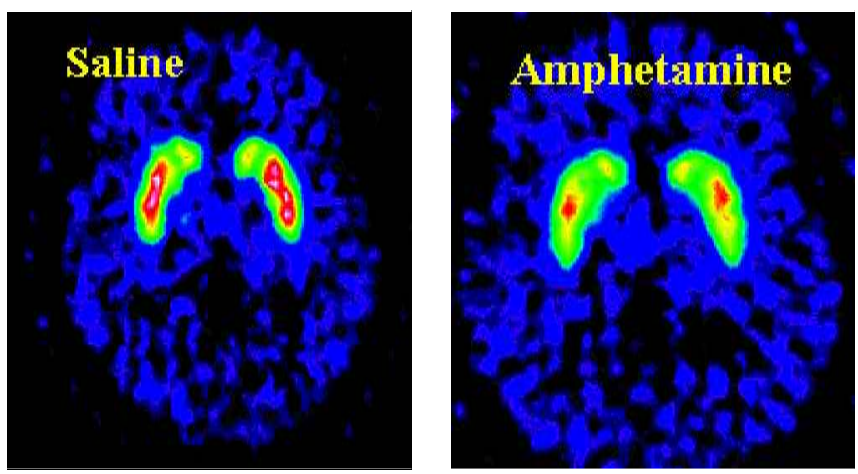

(a)

${ }^{11} \mathrm{C}$-raclopride binding in patient with Parkinson's disease Pre-graft

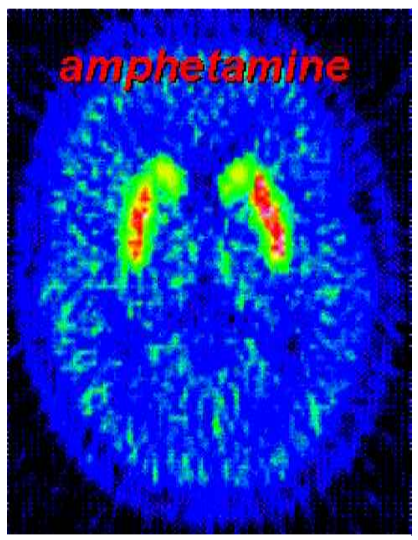

Post-graft

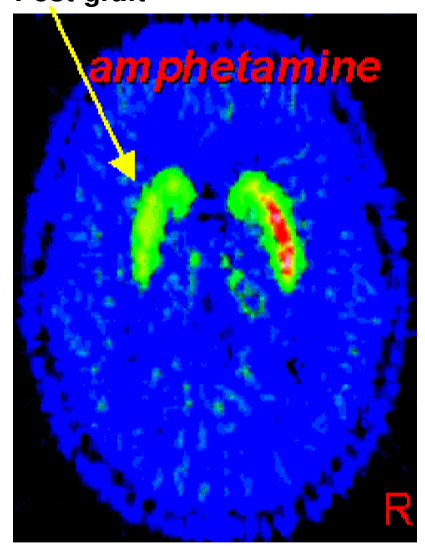

(b)
Video game playing
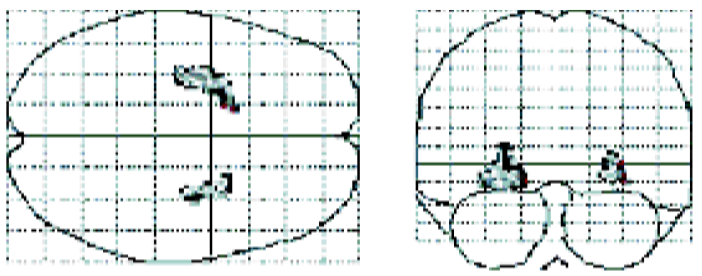

(c)

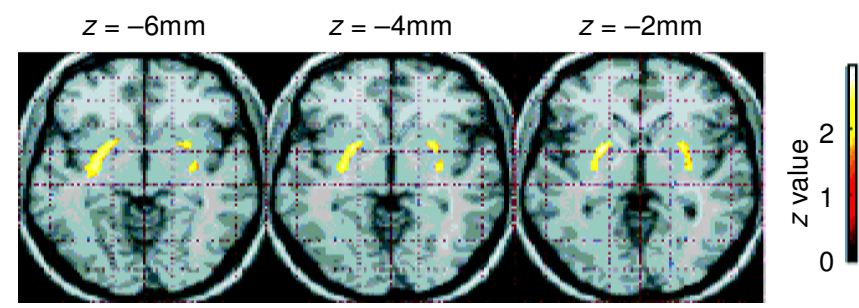

(d)

Fig 4. ${ }^{11} \mathrm{C}$-raclopride positron emission tomography studies of dopamine release. (a) Binding of ${ }^{11} \mathrm{C}$-raclopride decreases in the caudate and putamen following amphetamine challenge, as a result of striatal dopamine release. (b) Binding of ${ }^{11} \mathrm{C}$-raclopride decreases unilaterally in the putamen (arrow) following amphetamine challenge in a patient with Parkinson's disease with a unilateral tissue graft in the putamen. (c) Statistical parametric maps showing decreases of ${ }^{11} \mathrm{C}$-raclopride binding in the ventral striatum following a rewarded novel motor task. (d) Areas of reduced ${ }^{11} \mathrm{C}$-raclopride binding coregistered onto transverse template MRI images. (c), (d) Reproduced with permission from Koepp et al. ${ }^{22}$, copyright 1998 Nature, www.nature.com 


\section{Clinical applications of PET measurements of neurotransmitter release}

As discussed earlier, ${ }^{18} \mathrm{~F}$-DOPA, although providing evidence for graft survival in Parkinson's disease, does not prove that the graft is releasing dopamine, an important physiological end point in treating the disease. However, the sensitivity of ${ }^{11} \mathrm{C}$-raclopride binding to endogenous dopamine can be used to assess graft function. Figure $4 \mathrm{~b}$ shows PET scans of a single patient with Parkinson's disease before and after grafting. In the absence of the graft there was minimal ${ }^{11} \mathrm{C}$-raclopride displacement in the basal ganglia following amphetamine challenge, reflecting the loss of dopamine due to the illness. However, following a mesencephalic graft to the right putamen and amphetamine re-challenge there was a significant reduction in binding of ${ }^{11} \mathrm{C}$-raclopride in the region of the graft. The most plausible explanation for this result is that dopamine cell function in the region of the graft has been restored, permitting dopamine release and, hence, reduced binding of ${ }^{11} \mathrm{C}$-raclopride ${ }^{23}$.

This PET technique can also be used to test the dopamine over-activity hypothesis in schizophrenia. Two PET groups in the USA have recently shown an enhanced amphetamine effect in drug-free patients with schizophrenia, which, in conjunction with the ${ }^{18} \mathrm{~F}$-DOPA studies, provides the most compelling evidence yet to support the dopamine over-activity hypothesis ${ }^{19,24}$.

\section{Measuring functional activation effects}

PET methods can also be used to index the 'functional activity' of the brain by measuring blood flow as an index of neural activity. This is possible because of the established coupling between regional neural activity, glucose utilisation and blood flow in the human brain ${ }^{25}$. Over the last 10 years my colleagues and I have used these methods to study dopamine function in disease states. As discussed previously, there is substantial PET evidence of reduced dopamine function in Parkinson's disease and enhanced dopamine function in schizophrenia. Although these PET-signal changes were measured in the striatum, it is highly likely that abnormalities of dopamine function occur in other brain areas and affect neuronal circuitry, particularly function in the cortico-striatal loops. This has been tested in the Cyclotron Unit, in patients with Parkinson's disease and in unmedicated patients with schizophrenia. These experiments investigated whether dopamine modulation affected prefrontal function in either patient group (Fig 5a,b). In the Parkinson's disease group, subjects in the 'off state' showed a deficient prefrontal activation whilst undertaking a joystick task ${ }^{26}$. Similarly, in unmedicated schizophrenic patients there was a failure of activation in the anterior cingulate region of the prefrontal cortex during a verbal fluency task ${ }^{27,28}$. To modulate dopaminergic neurotransmission, a 'high dose' of apomorphine (a non-

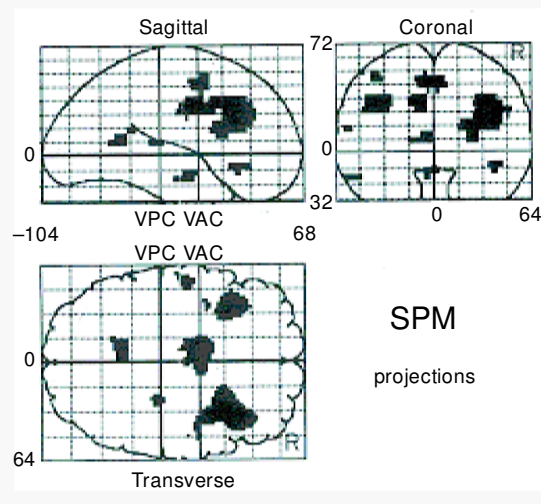

(a)

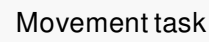

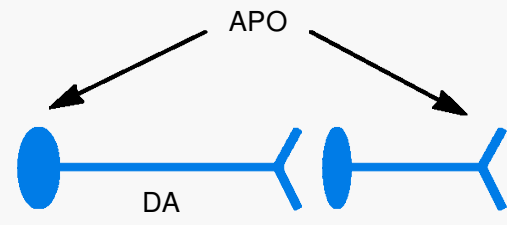

DA

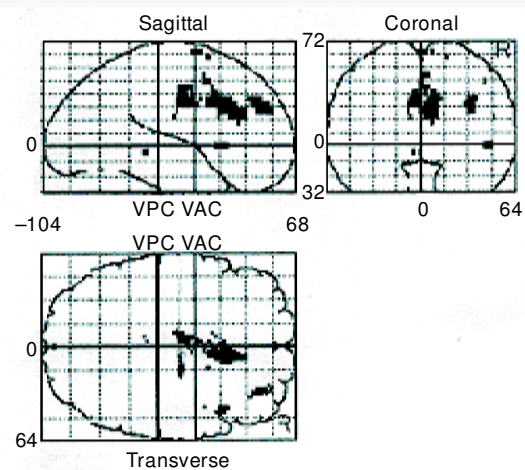

(b)

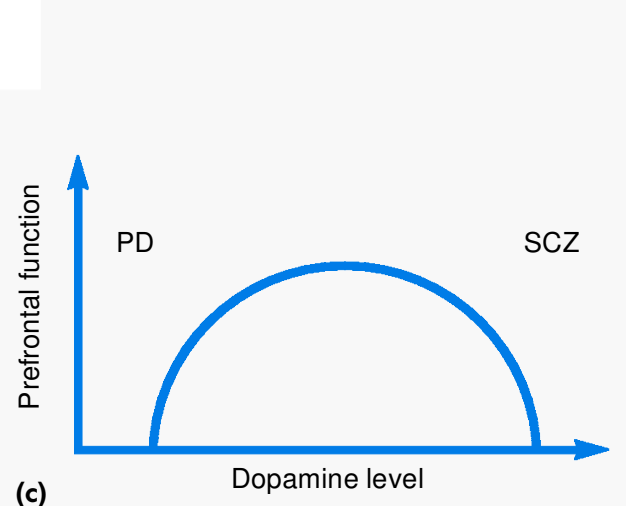

(c)

Cognitive task

Fig. 5. Positron emission tomography studies of the dopaminergic modulation of prefrontal activity. (a,b) Statistical parametric maps (SPM) showing augmentations of brain activations following (a) high-dose apomorphine (APO) administration to patients with Parkinson's disease and (b) low-dose apomorphine administration to patients with schizophrenia. Areas of increased activation are seen in 'glass-view brains' viewed from the side, behind and above. DA = dopamine. (c) Postulated graph of dopamine neurotransmission against prefrontal function showing inverted-U relationship. (a) Reproduced with permission from Jenkins et al., Ann Neurol $1992 ; 32: 749-57^{26}$. (b) Reproduced with permission from Fletcher et al., J Neurosci 1996;16:7055-62 ${ }^{28}$, copyright 1996 by the Society for Neuroscience. 
selective dopamine agonist) was used in patients with Parkinson's disease, and a 'low dose' of apomorphine was used in patients with schizophrenia. High-dose apomorphine (>2-3 mg) is used to treat Parkinson's disease, and stimulates postsynaptic dopamine receptors. In contrast, 'low-dose' apomorphine $(<0.7 \mathrm{mg})$ stimulates dopamine $\mathrm{D}_{2}$ autoreceptors to turn off dopamine neurotransmission. High-dose apomorphine restored prefrontal activation in Parkinson's disease patients performing the joystick activation task, and, likewise, low-dose apomorphine restored anterior-cingulate activation in patients with schizophrenia (Fig 5a,b). Thus, opposing pharmacological manipulations of dopamine neurotransmission restored prefrontal deficits in these two conditions. In Parkinson's disease, which is associated with hypodopaminergic activity, high-dose (postsynaptic) apomorphine restored function, whereas in schizophrenia, which is associated with hyperdopaminergic activity, low-dose (presynaptic) apomorphine restored normal prefrontal function. These data suggest an inverted-U shaped curve between dopamine neurotransmission and optimal function of the prefrontal cortex in humans (Fig 5c), as is the case in non-human primates ${ }^{29}$.

\section{Conclusions}

This brief review suggests that PET imaging is a versatile and powerful tool for investigating chemical neurotransmission in vivo. Although the number of neurotransmitter systems that can be adequately imaged is relatively small, compared with the number that are known to exist, fundamental basic and clinical information can be obtained. Already, unique insights into the living neurochemical brain are appearing, and, with further radiotracer developments, it is likely that we will see major inroads into our understanding of the neurochemistry of many neurological and psychiatric disorders.

\section{References}

1 McKusick VA. Genetic disorders of the human nervous system: a commentary. In: Schmitt FO, Bloom FE (ed). Molecular genetic neuroscience. New York: Raven Press, 1982: 401-5.

2 Acampora D, Barone P, Simeone A. Otx genes in corticogenesis and brain development. Cereb Cortex 1999;9:533-42.

3 Lai CS, Fisher SE, Hurst JA, Vargha-Khadem F, Monaco AP. A forkheaddomain gene is mutated in a severe speech and language disorder. Nature 2001;413:519-23.

4 Lesch KP, Mossner R. Genetically driven variation in serotonin uptake: is there a link to affective spectrum, neurodevelopmental, and neurodegenerative disorders? Biol Psychiatry 1998;44:179-92.

5 Lopez AD, Murray CC. The global burden of disease, 1990-2020. Nat Med 1998;4:1241-3.

6 Sedvall G, Farde L. Chemical brain anatomy in schizophrenia. Lancet 1995;346:743-9.

7 Grasby P, Malizia A, Bench C. Psychopharmacology - in vivo neurochemistry and pharmacology. Br Med Bull 1996;52:513-26.

8 Gunn RN, Gunn SR, Cunningham VJ. Positron emission tomography compartmental models. J Cereb Blood Flow Metab 2001;21:635-52.

9 Perez V, Soler J, Puigdemont D, Alvarez E, Artigas F. A double-blind, randomized, placebo-controlled trial of pindolol augmentation in depressive patients resistant to serotonin reuptake inhibitors. Arch Gen Psychiatry 1999;56:375-9.
10 Blier P, de Montigny C, Chaput Y. Electrophysiological assessment of the effects of antidepressant treatments on the efficacy of 5-HT neurotransmission. Clin Neuropharmacol 1988;11(Suppl. 2):S1-S10.

11 Blier P, Pineyro G, el Mansari M, Bergeron R, de Montigny C. Role of somatodendritic 5-HT autoreceptors in modulating 5-HT neurotransmission. Ann N Y Acad Sci 1998;861:204-16.

12 Artigas F. Pindolol, 5-hydroxytryptamine, and antidepressant augmentation. Arch Gen Psychiatry 1995;52:969-71.

13 Artigas F, Celada P, Laruelle M, Adell A. How does pindolol improve antidepressant action? Trends Pharmacol Sci 2001;22:224-8.

14 Pike VW, McCarron JA, Lammertsma AA, Osman S, et al. Exquisite delineation of $5-\mathrm{HT}_{1 \mathrm{~A}}$ receptors in human brain with $\mathrm{PET}$ and \{carbonyl- ${ }^{11}$ C\}WAY-100635. Eur J Pharmacol 1996;301:R5-R7.

15 Rabiner EA, Gunn RN, Castro ME, Sargent PA, et al. Beta-blocker binding to human $5-\mathrm{HT}_{1 \mathrm{~A}}$ receptors in vivo and in vitro: implications for antidepressant therapy. Neuropsychopharmacology 2000;23:285-93.

16 Brooks DJ, Piccini P. Non-invasive in vivo imaging of transplant function. Prog Brain Res 2000;127:321-32.

17 Hietala J, Syvalahti E, Vuorio K, Rakkolainen V, et al. Presynaptic dopamine function in striatum of neuroleptic-naive schizophrenic patients. Lancet 1995;346:1130-1.

18 Volkow ND, Wang GJ, Fowler JS, Logan J, et al. Imaging endogenous dopamine competition with $\left\{{ }^{11} \mathrm{C}\right\}$ raclopride in the human brain. Synapse 1994;16:255-62.

19 Laruelle M. Imaging synaptic neurotransmission with in vivo binding competition techniques: a critical review. J Cereb Blood Flow Metab 2000;20:423-51.

20 Schultz W, Apicella P, Ljungberg T. Responses of monkey dopamine neurons to reward and conditioned stimuli during successive steps of learning a delayed response task. J Neurosci 1993;13:900-13.

21 Schultz W, Dayan P, Montague PR. A neural substrate of prediction and reward. Science 1997;275:1593-9.

22 Koepp MJ, Gunn RN, Lawrence AD, Cunningham VJ, et al. Evidence for striatal dopamine release during a video game. Nature 1998;393: 266-8.

23 Piccini P, Brooks DJ, Bjorklund A, Gunn RN, et al. Dopamine release from nigral transplants visualized in vivo in a Parkinson's patient. Nat Neurosci 1999;2:1137-40.

24 Laruelle M, Abi-Dargham A, van Dyck CH, Gil R, et al. Single photon emission computerized tomography imaging of amphetamine-induced dopamine release in drug-free schizophrenic subjects. Proc Natl Acad Sci USA 1996;93:9235-40.

25 Raichle ME. Behind the scenes of functional brain imaging: a historical and physiological perspective. Proc Natl Acad Sci USA 1998;95:765-72.

26 Jenkins IH, Fernandez W, Playford ED, Lees AJ, et al. Impaired activation of the supplementary motor area in Parkinson's disease is reversed when akinesia is treated with apomorphine. Ann Neurol 1992;32: 749-57.

27 Dolan RJ, Fletcher P, Frith CD, Friston KJ, et al. Dopaminergic modulation of impaired cognitive activation in the anterior cingulate cortex in schizophrenia. Nature 1995;378:180-2.

28 Fletcher PC, Frith CD, Grasby PM, Friston KJ, Dolan RJ. Local and distributed effects of apomorphine on fronto-temporal function in acute unmedicated schizophrenia. J Neurosci 1996;16:7055-62.

29 Lidow MS, Williams GV, Goldman-Rakic PS. The cerebral cortex: a case for a common site of action of antipsychotics. Trends Pharmacol Sci 1998;19:136-40.

Address for correspondence: Professor PM Grasby, Clinical Sciences Centre, MRC Cyclotron Building, Imperial College School of Medicine, Hammersmith Hospital, Du Cane Road, London W12 ONN 